\title{
A Study of Fostering College English Students' Awareness of Cultural Comparison in Chinese Classrooms
}

\author{
Libin Duan \\ Sichuan Normal University, Chengdu, China \\ Email: duanlb@sicnu.edu.cn \\ Received 12 April 2016; accepted 17 May 2016; published 20 May 2016 \\ Copyright (C 2016 by author and Scientific Research Publishing Inc. \\ This work is licensed under the Creative Commons Attribution International License (CC BY). \\ http://creativecommons.org/licenses/by/4.0/ \\ (c) (i) Open Access
}

\begin{abstract}
The study examines the effectiveness of different culture-oriented approaches to foster college English students' awareness of cultural comparison in Chinese classrooms. A survey about college students' status quo in English learning indicates that they are poor in western cultural knowledge, especially lack cultural comparative sense and ability. Therefore, based on the second language acquisition theory and the constructivism theory, the study aims at exploring some effective culture-oriented approaches to develop Chinese college English students' cross-cultural communication ability. After a term's experimental teaching in the author's two classes, and data collection and analysis, it is concluded that the following approaches are effective: duty report, various classroom activities, self-access study, hosting the online instruction, etc.
\end{abstract}

\section{Keywords}

Cultural Comparison, College English Students, Constructivism, Second Language Acquisition, Culture-Oriented Approach

\section{Introduction}

Under the guidance of Chinese Education Ministry, we have conducted whole scale reform in college English teaching since 2004 when College English Curriculum Requirements (For Trial Implementation) (CECR) was published. Many universities have tried to apply information technology and various effective teaching models and approaches to college English course, and made great achievements in developing students' English proficiency in reading, writing, listening and speaking, etc. But due to the limitation of learning time and lack of English environment, Chinese college students still have weaknesses in English practical ability such as writing 
and speaking. They know little about English culture, therefore often feel embarrassed when communicating with native English speakers. The author conducted a survey about college students' status quo in English learning, which indicates that they have little sense of culture, especially of cultural comparative analysis. Therefore, according to CECR [1], and based on the second language acquisition theory and constructivism theory, the study aims at exploring some effective culture-oriented approaches to enrich Chinese college English students' cultural comparative knowledge and develop their cross-cultural communication ability.

My research questions are:

1) Will culture-oriented approaches contribute to the development of students' cross-cultural communication ability?

2) How will culture-oriented approaches contribute to the development of students' cross-cultural communication ability?

3) What is the pedagogical implication of culture-oriented approaches' contribution to fostering students' cross-cultural communication ability?

\section{Literature Review}

\subsection{Definition of Culture}

There is no standard definition of the term "culture". People from different countries and in different times give different definitions to the simple word "culture". According to the New Oxford Dictionary of English, "culture" refers to the arts and other manifestations of human intellectual achievement regarded collectively [2]. English anthropologist Edward Tylor explains "culture" in his book Primitive Culture, "Culture is inevasible and complicated, including knowledge, belief, art, moral, law, custom, ability, and habit learned in society” [3]. Simply speaking, "culture" refers to the series of languages, styles, customs, beliefs, values, experiences and knowledge shared by a group of people. They may live in the same area or country, or belong to the same ethnic group or the same age group, etc.

\subsection{Relationship between Culture and EFL Teaching}

It is evident that culture is often manifested and communicated through language, and at the same time language is restricted by culture and functions in it. Thus foreign language teaching, such as EFL teaching, cannot be successful without the transmission of foreign culture. That is to say, For Chinese College English teachers, they should not only teach how and what to say in English in a certain cross-cultural context, but also adopt different approaches to develop their students' awareness of cultural comparison, which is the essence of culture-oriented approach. As Claire Kramsch points out, we can develop our linguistic and communicative competence by improving our aesthetic and critic consciousness, namely "critical cross-cultural literacy" [4].

\subsection{Second Language Acquisition}

Research on second-language acquisition (SLA) began in the 1960s, and incorporated with the academic achievement in other fields since the 1980s. Therefore such incorporation results in many different branches or models of SLA theory, such as systemic functional linguistics, socio-cultural theory, cognitive linguistics, psychological linguistics, the relation between SLA and such factors as classroom instruction, age, learning strategies, and the relation between language input and output, etc.

The most influential SLA theory about language input and output is Stephen Krashen's input hypothesis. He greatly stresses the significance of input, claiming that second-language acquisition is dependent on the comprehensible input [5].

According to Stephen Krashen's input hypothesis, The EFL teachers should offer many opportunities for students to receive language input as much as possible so that they can effectively improve their English competence.

On the other hand, Canadian linguist M. Swain puts forward his output hypothesis, and insists that output plays a more prominent role in second language acquisition [6].

Another prestigious British expert Jeremy Harmer emphasizes the importance of a teacher's motivating his students to join in the activities and use the target language in the classrooms. That is to say, he creates the necessary elements for teaching language: E (engage), S (study), A (activate), namely the ESA model [7]. 
Other models teachers prefer to use in EFL teaching are: PPP (presentation, practice and production), TaskBased Learning, problem-based learning, project-based learning, and immersion learning, etc.

\subsection{The Constructivism Theory}

The learning theory constructivism believes that learners acquire knowledge and meaning from an interaction between their new experiences and their old conceptions. Various approaches in pedagogy, such as scaffolding approach, communicative approach, etc., derive from constructivist theory. The representative experts are Jean Piaget and Vygotsky.

Jean Piaget explores the mechanism of knowledge internalization by learners, and discovers that individuals construct new knowledge from their experiences by means of accommodation and assimilation [8].

Another influential constructivism psychologist and educator is Vygotsky from Russian. His ZPD (Zone of Proximal Development) theory stresses the vital role played by social interaction and cooperative learning in constructing new knowledge [8].

The essence of constructivism is to let the learners make their own inferences, discoveries and conclusions through different kinds of realistic activities.

\section{Methodology}

After reading and analyzing the above academic literature concerning learning, especially second language acquisition, I decided to explore some culture-oriented approaches to improve the effectiveness of college English teaching in Chinese classrooms, and to foster the students' awareness of cultural comparison.

\subsection{Participants}

In this study the participants were two college English classes chosen from Grade 2014 of Sichuan Normal University where I work. As a rule of our university, the freshmen have to take part in an English placement test held by the college English department after they register for the first term. Then we divide these students into over 100 college English classes based on their score in the test. The English level of the students in each class is basically the same, and every class consists of about 60 students from one or two colleges. All the college English teachers are from college English department, and the required college English teaching will be conducted for 2 to 4 terms according to the English level of each class, in accordance with the same series of textbooks, the same syllabus, course design, teaching plan. Furthermore, the students at the same level will take the same end-of-the-term exam, and the exam papers will be collectively evaluated and graded according to the same evaluation standard.

I did this empirical research on the effectiveness of different kinds of culture-oriented approaches applied to my two English classes of Grade 2014. They are Level B students, the comparatively advanced learners among Grade 2014 students. The most advanced learners are Level A, and the rest students are Level C. The students of both classes are science or engineering majors. There are 60 students from the experimental class, among which 31 students are from College of Computer Science, and the rest 29 students are from Engineering College. And there are 62 students from the control class, among which 30 students are from College of Computer Science, and the rest 32 students are from College of Physics and Electronic Engineering.

\subsection{Instrumentation}

The author will do an experimental teaching to explore the effectiveness of different kinds of teaching approaches aiming at improving students' awareness of cultural comparison in the process of English learning as well as improving students' score in the end-of-the-term exam.

The teaching approaches' design is based on Stephen Krashen, Merrill Swain and Jeremy Harmer's second language acquisition theories, and Jean Piaget and Vygotsky's constructivism theory. Besides I only adopted the experimental teaching to one of the two classes, and at the same time taught the other class, the control class, under the guidance of our teaching and research unit.

The experimental teaching lasted for one term, and I collected the following data and did the data analysis before and after that:

1) the students' score of the placement test at the beginning of the first term, namely the pre-test; 
2) the students' score of the final exam for the first term, namely the post-test;

3) the questionnaire on the students from the experimental class after the final exam.

As for the questionnaire, I first asked the students if they agreed that it was necessary to develop the students' cross-cultural communication ability in college English teaching. If a student's answer is "Yes", then he or she was invited to answer Questions 1 to 11 . Otherwise, if a student's answer is "No", then he or she was invited to answer Questions 12 to 18 . Questions 1 to 11 are about how often each student had learned cross-cultural communication knowledge from each approach. Questions 12 to 18 are the reasons why each student didn't agree that it was necessary to develop the students' cross-cultural communication ability in college English teaching. For Questions 1 to 11, the students are asked to choose one from 5, 4, 3, 2, or 1. According to Lickert Scale, 5 means he or she "usually learn cultural knowledge from it", 4, 3, 2 and 1 respectively means he or she "frequently", "often”, "sometimes”, and "occasionally” learns cultural knowledge from it. For Questions 12 to 18, the students are asked to choose one from 5, 4, 3, 2, or 1, and according to Lickert Scale, 5, 4, 3, 2 and 1 respectively means he or she "agrees strongly", "agrees”, "agrees slightly", “disagrees” and "disagrees strongly".

In addition, I interviewed some of the students from the experimental class after the experimental teaching so as to help me analyze and discuss the data collected above.

\subsection{Procedure}

According to the course design of our department, for each college English class we have four hours' teaching per week, among which one hour is assigned to listening or speaking training, and the other three hours is assigned to reading. Besides each class will have two hours' self-access study in the computer classroom every three weeks instead of reading class. Apart from the traditional teaching in the classroom, every week an English teacher is supposed to instruct his students online for one hour per class. The purpose of online instruction is to offer timely guidance to students for their autonomy study after class.

In my research I follow the course design to teach both my control class and experimental class, but adopt more culture-oriented approaches in my experimental class in the following way (as shown in Figure 1):

1) In reading teaching, I assigned various practical and culture-oriented assignments to my students so as to promote their understanding of western culture, such as duty report, pair work, and class discussion;

2) For self-access listening class and comprehensive learning class in the computer classroom, I gave students some useful learning strategies including culture-related knowledge in advance;

3) For online instruction time, I didn't wait for the students to ask me questions about English learning. On the contrary, I asked the students to act as a host or hostess to lead his classmates to have an online forum about English learning, and English culture. I just facilitated and monitored their online forum, and gave timely help

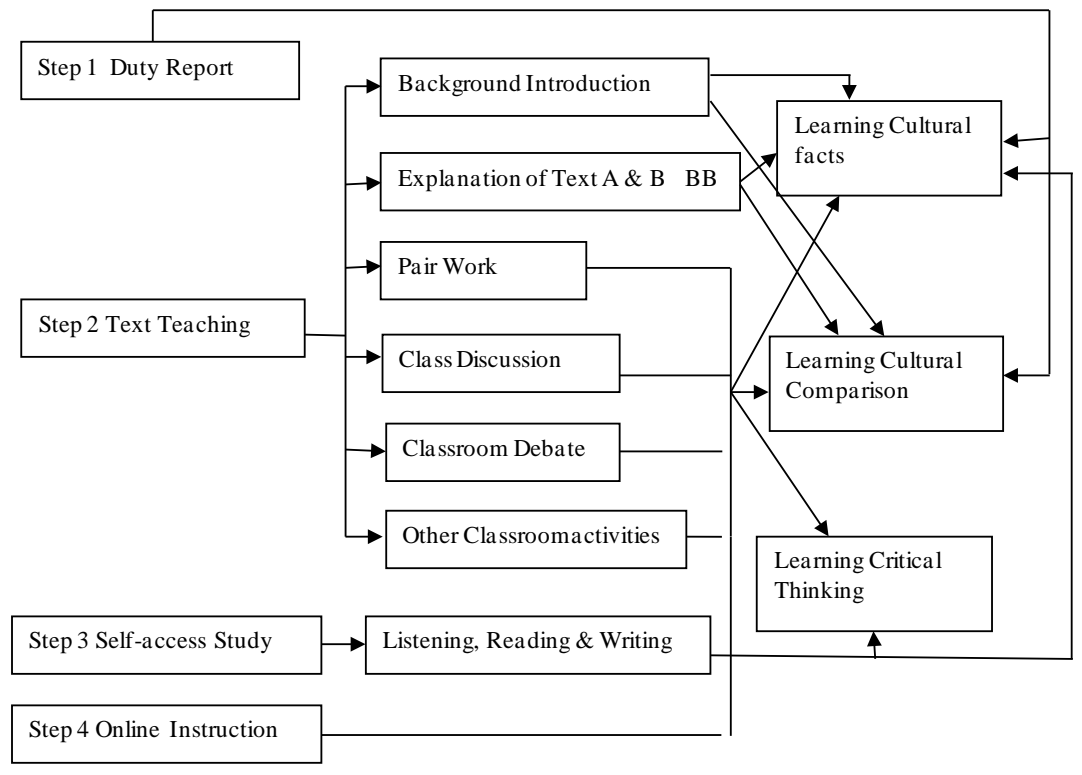

Figure 1. Procedure of my experimental teaching. 
whenever they met with some difficulty.

I follow the three principles when giving the experimental teaching to my students:

1) Use authentic teaching materials as much as possible, for example, I show my pictures taken in America to show them the cultural background.

2) Ask the students to speak out or to write their true feelings or their own opinions about whatever they talk about in class or in online instruction, or whatever they write.

3) Give timely and appropriate guidance to the students in the process of teaching and learning, and gradually promote their awareness of cultural comparison.

\section{Results}

After collecting all the data before and after the experimental teaching, I used SPSS 17 to analyze them and answer my research questions. Here is the result:

1) Will culture-oriented approaches contribute to the development of students' cross-cultural communication ability?

As for the mean scores, let's look at Table 1. The pre-test is 69.94, while the post-test is $75.29,5.35$ higher than the pre-test, which shows that students have made progress in the scores of the final exam. On the other hand, for Table 2, the pre-test is 69.88 , while the post-test is 78.72 , 8.84 higher than the pre-test, which shows that students in the experimental class made more progress in the scores of the final exam. As there is a lot of culture-related content in the placement test and the final exam, such as reading comprehension, passage translation, etc. we may conclude that although the control class students' score improved after a term's study, the culture-oriented approaches contribute more to the development of students' cross-cultural communication ability.

As for the standard deviation, the control class is 1.470 and 5.611, while the experimental class is 1.585 and 5.606. Both Table 1 and Table 2 show that the score gap of each student in this aspect is increasing, which is not a good phenomenon. But my interview with the students reveals that some students felt rather relaxed after being enrolled in the university and didn't work as hard as they did in senior high school, which led to the decrease of their score in the final exam. Some other students were puzzled by the new environment, and didn't know how to make full use of their free time to study well. Therefore the interview justifies the increase of the standard deviation in Table 1 and Table 2.

After one term's experimental teaching and the final exam, I did a questionnaire on the students from the experimental class. Here is the result:

2) How will culture-oriented approaches contribute to the development of students' cross-cultural communication ability?

Firstly, I asked them to answer this yes or no question: Do you like learning cultural knowledge from my English class? If your answer is No, please go on to answer the first group of questions, which involves some typical reasons why the student doesn't like learning cultural knowledge from my English class. The result is that only 3 students answered "No" among 60 students. The number is so small that I haven't analyzed their reasons.

Table 1. Statistics comparison of the control class between the pre-test and the post-test.

\begin{tabular}{rccc}
\hline & Mean & N & Std. Deviation \\
\hline Pre-test & 69.94 & 62 & 1.470 \\
Post-test & 75.29 & 62 & 5.611 \\
\hline
\end{tabular}

Table 2. Statistics comparison of the experimental class between the pre-test and the posttest.

\begin{tabular}{cccc} 
& Mean & N & Std. Deviation \\
\hline Pre-test & 69.88 & 60 & 1.585 \\
Post-test & 78.72 & 60 & 5.606 \\
\hline
\end{tabular}


Second, If your answer is yes, please move on to answer the second group of questions, which intends to survey to what extent each culture-oriented approach contributes to the development of students' cross-cultural communication ability. My question is:

How much cross-cultural knowledge do you think you have learned from different steps of my English teaching? For each question, If you have learned the most, you should choose answer 5. Likewise, if you have learned the least, you should choose answer 1. Otherwise, you should choose answer 2, 3, or 4 according to your own situation.

Altogether 60 students submitted their answers, and I did some statistical analysis of them. The following tables show the series of result from my analysis (Tables 3-13).

Frequency tables:

Table 3. Listen to the duty report.

\begin{tabular}{|c|c|c|c|c|c|}
\hline & & Frequency & Percentage & Valid Percentage & Accumulative Percentage \\
\hline & occasionally learn cultural knowledge from it & 2 & 3.3 & 3.5 & 3.5 \\
\hline \multirow{4}{*}{ Valid } & sometimes learn cultural knowledge from it & 8 & 13.3 & 14.0 & 17.5 \\
\hline & often learn cultural knowledge from it & 20 & 33.3 & 35.1 & 52.6 \\
\hline & frequently learn cultural knowledge from it & 13 & 21.7 & 22.8 & 75.4 \\
\hline & usually learn cultural knowledge from it & 14 & 23.3 & 24.6 & 100.0 \\
\hline \multirow{3}{*}{ Missing } & Total & 57 & 95.0 & 100.0 & \\
\hline & System & 3 & 5.0 & & \\
\hline & Total & 60 & 100.0 & & \\
\hline
\end{tabular}

Table 4. Listen to the text background information.

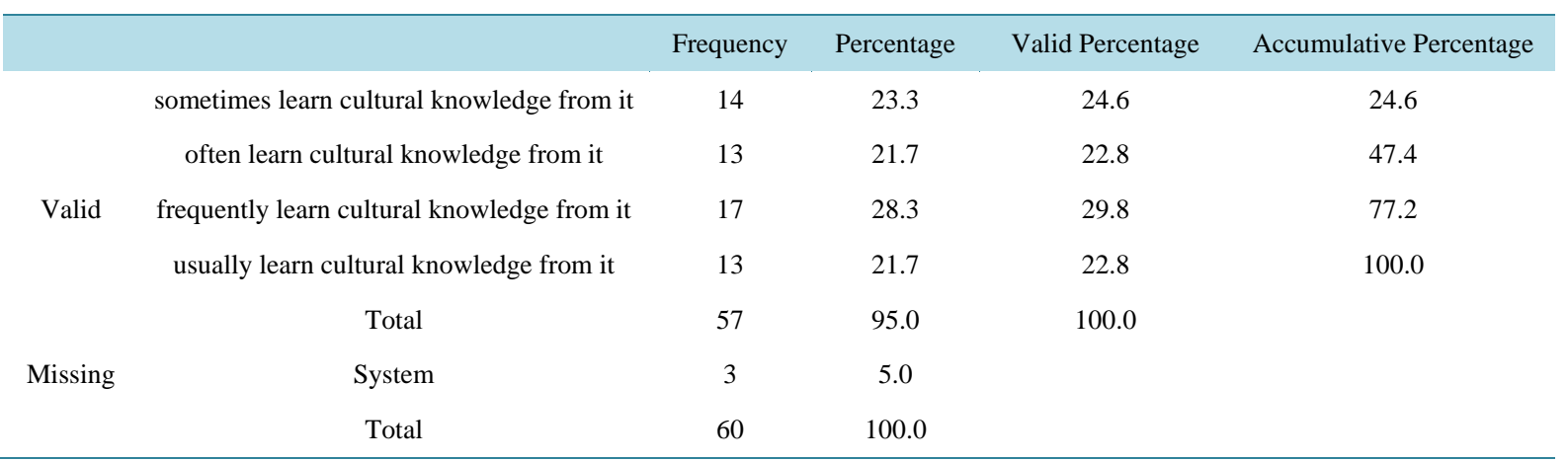

Table 5. Listen to the explanation to Text A \&Text B.

\begin{tabular}{|c|c|c|c|c|c|}
\hline & & Frequency & Percentage & Valid Percentage & Accumulative Percentage \\
\hline & occasionally learn cultural knowledge from it & 3 & 5.0 & 5.3 & 5.3 \\
\hline \multirow{4}{*}{ Valid } & sometimes learn cultural knowledge from it & 9 & 15.0 & 15.8 & 21.1 \\
\hline & often learn cultural knowledge from it & 17 & 28.3 & 29.8 & 50.9 \\
\hline & frequently learn cultural knowledge from it & 17 & 28.3 & 29.8 & 80.7 \\
\hline & usually learn cultural knowledge from it & 11 & 18.3 & 19.3 & 100.0 \\
\hline \multirow{3}{*}{ Missing } & Total & 57 & 95.0 & 100.0 & \\
\hline & System & 3 & 5.0 & & \\
\hline & Total & 60 & 100.0 & & \\
\hline
\end{tabular}


Table 6. Join in the online instruction activities.

\begin{tabular}{|c|c|c|c|c|c|}
\hline & & Frequency & Percentage & Valid Percentage & Accumulative Percentage \\
\hline & occasionally learn cultural knowledge from it & 8 & 13.3 & 14.0 & 14.0 \\
\hline \multirow{4}{*}{ Valid } & sometimes learn cultural knowledge from it & 15 & 25.0 & 26.3 & 40.4 \\
\hline & often learn cultural knowledge from it & 16 & 26.7 & 28.1 & 68.4 \\
\hline & frequently learn cultural knowledge from it & 11 & 18.3 & 19.3 & 87.7 \\
\hline & usually learn cultural knowledge from it & 7 & 11.7 & 12.3 & 100.0 \\
\hline \multirow{3}{*}{ Missing } & Total & 57 & 95.0 & 100.0 & \\
\hline & System & 3 & 5.0 & & \\
\hline & Total & 60 & 100.0 & & \\
\hline
\end{tabular}

Table 7. Take the oral English class.

\begin{tabular}{|c|c|c|c|c|c|}
\hline & & Frequency & Percentage & Valid Percentage & Accumulative Percentage \\
\hline & occasionally learn cultural knowledge from it & 5 & 8.3 & 8.8 & 8.8 \\
\hline \multirow{5}{*}{ Valid } & sometimes learn cultural knowledge from it & 9 & 15.0 & 15.8 & 24.6 \\
\hline & often learn cultural knowledge from it & 17 & 28.3 & 29.8 & 54.4 \\
\hline & & & & & \\
\hline & frequently learn cultural knowledge from it & 15 & 25.0 & 26.3 & 80.7 \\
\hline & usually learn cultural knowledge from it & 11 & 18.3 & 19.3 & 100.0 \\
\hline \multirow{3}{*}{ Missing } & Total & 57 & 95.0 & 100.0 & \\
\hline & System & 3 & 5.0 & & \\
\hline & Total & 60 & 100.0 & & \\
\hline
\end{tabular}

Table 8. Do exercises after each text.

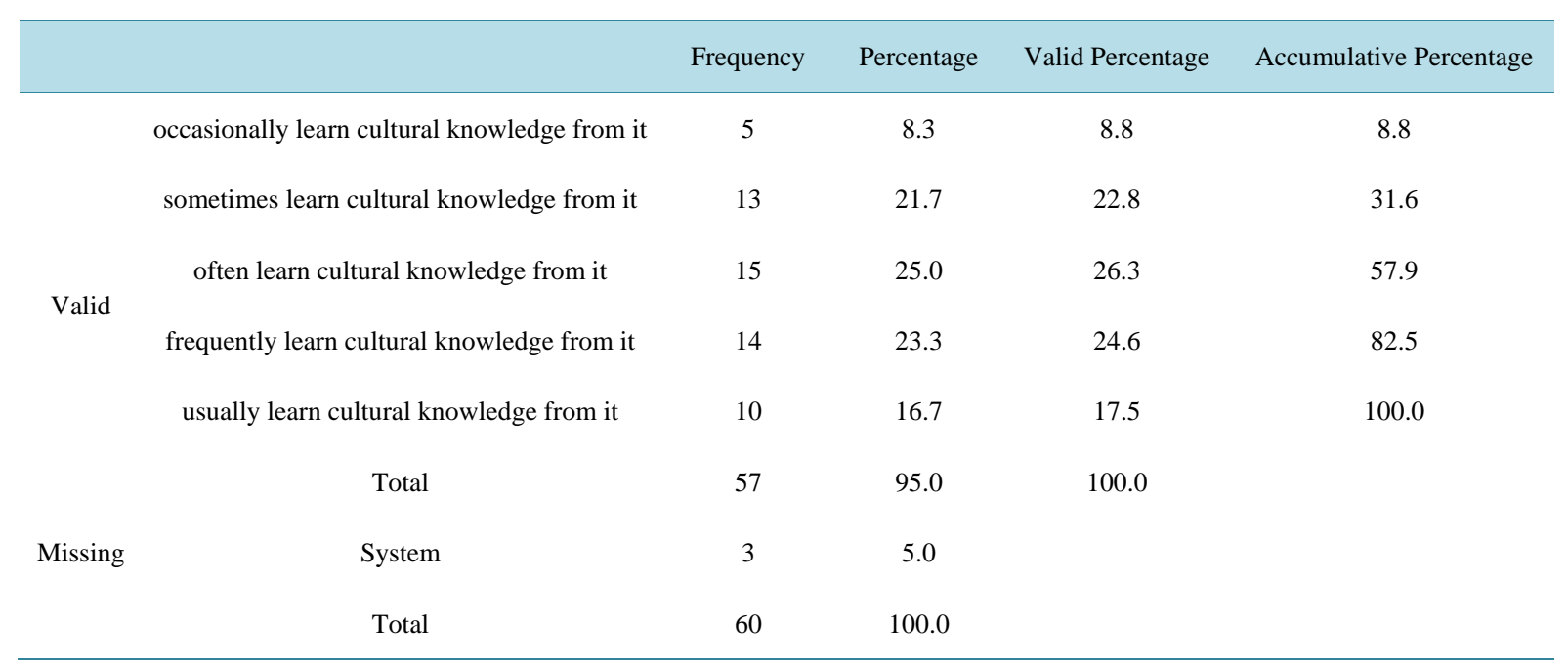


Table 9. Join in the pair work.

\begin{tabular}{|c|c|c|c|c|c|}
\hline & & Frequency & Percentage & Valid Percentage & Accumulative Percentage \\
\hline & occasionally learn cultural knowledge from it & 4 & 6.7 & 7.0 & 7.0 \\
\hline \multirow{5}{*}{ Valid } & sometimes learn cultural knowledge from it & 11 & 18.3 & 19.3 & 26.3 \\
\hline & often learn cultural knowledge from it & 21 & 35.0 & 36.8 & 63.2 \\
\hline & & & & & \\
\hline & frequently learn cultural knowledge from it & 12 & 20.0 & 21.1 & 84.2 \\
\hline & usually learn cultural knowledge from it & 9 & 15.0 & 15.8 & 100.0 \\
\hline \multirow{3}{*}{ Missing } & Total & 57 & 95.0 & 100.0 & \\
\hline & System & 3 & 5.0 & & \\
\hline & Total & 60 & 100.0 & & \\
\hline
\end{tabular}

\section{Table 10. Join in the class discussion.}

\begin{tabular}{|c|c|c|c|c|c|}
\hline & & Frequency & Percentage & Valid Percentage & Accumulative Percentage \\
\hline & occasionally learn cultural knowledge from it & 2 & 3.3 & 3.5 & 3.5 \\
\hline \multirow{5}{*}{ Valid } & sometimes learn cultural knowledge from it & 16 & 26.7 & 28.1 & 31.6 \\
\hline & often learn cultural knowledge from it & 16 & 26.7 & 28.1 & 59.6 \\
\hline & & & & & \\
\hline & frequently learn cultural knowledge from it & 14 & 23.3 & 24.6 & 84.2 \\
\hline & usually learn cultural knowledge from it & 9 & 15.0 & 15.8 & 100.0 \\
\hline \multirow{3}{*}{ Missing } & Total & 57 & 95.0 & 100.0 & \\
\hline & System & 3 & 5.0 & & \\
\hline & Total & 60 & 100.0 & & \\
\hline
\end{tabular}

Table 11. Prepare for my duty report or host/hostess task.

\begin{tabular}{|c|c|c|c|c|c|}
\hline & & Frequency & Percentage & Valid Percentage & Accumulative Percentage \\
\hline & sometimes learn cultural knowledge from it & 6 & 10.0 & 10.5 & 10.5 \\
\hline \multirow{3}{*}{ Valid } & often learn cultural knowledge from it & 10 & 16.7 & 17.5 & 28.1 \\
\hline & frequently learn cultural knowledge from it & 18 & 30.0 & 31.6 & 59.6 \\
\hline & usually learn cultural knowledge from it & 23 & 38.3 & 40.4 & 100.0 \\
\hline \multirow{3}{*}{ Missing } & Total & 57 & 95.0 & 100.0 & \\
\hline & System & 3 & 5.0 & & \\
\hline & Total & 60 & 100.0 & & \\
\hline
\end{tabular}


Table 12. Take the listening class in the computer room.

\begin{tabular}{|c|c|c|c|c|c|}
\hline & & Frequency & Percentage & Valid Percentage & Accumulative Percentage \\
\hline & occasionally learn cultural knowledge from it & 1 & 1.7 & 1.8 & 1.8 \\
\hline \multirow{4}{*}{ Valid } & sometimes learn cultural knowledge from it & 12 & 20.0 & 21.1 & 22.8 \\
\hline & often learn cultural knowledge from it & 11 & 18.3 & 19.3 & 42.1 \\
\hline & frequently learn cultural knowledge from it & 19 & 31.7 & 33.3 & 75.4 \\
\hline & usually learn cultural knowledge from it & 14 & 23.3 & 24.6 & 100.0 \\
\hline \multirow{3}{*}{ Missing } & Total & 57 & 95.0 & 100.0 & \\
\hline & System & 3 & 5.0 & & \\
\hline & Total & 60 & 100.0 & & \\
\hline
\end{tabular}

Table 13. Take the self-study class in the computer room.

\begin{tabular}{|c|c|c|c|c|c|}
\hline & & Frequency & Percentage & Valid Percentage & Accumulative Percentage \\
\hline & occasionally learn cultural knowledge from it & 1 & 1.7 & 1.8 & 1.8 \\
\hline \multirow{4}{*}{ Valid } & sometimes learn cultural knowledge from it & 10 & 16.7 & 17.5 & 19.3 \\
\hline & often learn cultural knowledge from it & 18 & 30.0 & 31.6 & 50.9 \\
\hline & frequently learn cultural knowledge from it & 13 & 21.7 & 22.8 & 73.7 \\
\hline & usually learn cultural knowledge from it & 15 & 25.0 & 26.3 & 100.0 \\
\hline \multirow{3}{*}{ Missing } & Total & 57 & 95.0 & 100.0 & \\
\hline & System & 3 & 5.0 & & \\
\hline & Total & 60 & 100.0 & & \\
\hline
\end{tabular}

\section{Findings and Discussion}

This statistical analysis result is consistent with the result of my interview with my students. Both results show that:

1) Students are interested in cultural-oriented teaching, because only 3 students say they don't like learning cross-cultural knowledge from my English class;

2) What students like most is learning cultural knowledge by doing and exploring, because more than 70 percent of students say they have learned a lot of cross-cultural knowledge from preparing for their duty report or host/hostess work of the online instruction, which is the highest among all the teaching approaches; Students also give the positive feedback to self-access study in the computer classroom. This result proves Krashen, Swain, Harmer's theories and constructivism learning theories, because in the computer classroom, the students may control the learning content and time by themselves and get the most effective language input. Doing duty reports and hosting the online instructions are realistic and interactive learning activities, and students are free to choose their favorite topics to talk about and discuss with their classmates. Besides, in order to perform well and leave good impressions on the teacher and classmates, the duty reporters and online instruction hosts usually make efforts to prepare for their presentation or discussion. As a result, the students are greatly involved in such activities and have learned the most from such culture-oriented approaches.

3) The students' opinions disagree on some teaching approaches, such as listen to the duty report, background introduction, and other traditional ways of teaching. These approaches tend to directly impart knowledge to students, and leave little time for students to reflect and explore, so that some students feel less challenging and interesting. But other students are accustomed to the traditional learning strategy of listening to the teacher and 
taking notes and memorizing language points, therefore they can still learn a lot from the traditional approach.

4) What students learn least from is online instruction, pair work, and class discussion. These are interactive activities, so that only those students who have fully prepared and are active in such activities can learn a lot. Therefore such approaches are less productive in my class mainly for the following reasons: First, I didn't tell them exactly how their performance would be related to their final score so that they didn't feel the pressure to actively join in and earn their score. Second, they are non-English majors and have to spend a lot of time in learning the subjects most closely related to their major. Third, due to the poor preparation and weak motivation, the students feel it hard to freely express their ideas in English, and don't feel embarrassed when they can't find the exact words and sentence patterns to speak out their mind.

\section{Pedagogical Implications}

My third research question is about the pedagogical implications of my research:

3) What is the pedagogical implication of culture-oriented approaches' contribution to fostering students' cross-cultural communication ability?

Based on the above data analysis, the author suggests that the college English teachers learn from the following positive and negative pedagogical implications. They may adopt some effective culture-oriented approaches, and do further research to overcome the weak points of other less effective approaches so as to further foster students' cross-cultural communication ability.

In the future, the author should continue to adopt some effective culture-oriented approaches, such as duty report, online instruction host, etc. Meanwhile, she should also improve some traditional teaching approaches, for instance, ask the students to comment on the duty report, search information about the cultural background, compare the differences and similarities between Chinese and western culture, comment on western culture, etc.

In addition, it's necessary to apply more approaches to motivate the students to become interested in the cultural activities in the classroom and online instructions. For example, the author may ask the students some interesting questions or let them play some games before she presents the background introduction to them. She may also use some beautiful pictures, humorous videos to teach them cultural background knowledge. During their pair work and discussion, she should offer examples and timely instruction or encouragement. She may ask the students to discuss about when to tolerate and assimilate the foreign culture and when to stick to our own culture in the process of cross-cultural communication, etc.

In a word, cultural awareness had always been regarded as an important concept in applied linguistics [9]. College English teachers should enrich their own knowledge about foreign culture and English language while improving their teaching methods so as to foster college students' awareness of cultural comparison, and act as a better English learning designer, cooperator, and facilitator in the process of English learning.

\section{References}

[1] Higher Education Department of Education Ministry (2004) College English Curriculum Requirements (For Trial Implementation). Shanghai Foreign Language Education Press, Shanghai.

[2] Pearsall, J., Ed. (2001) The New Oxford Dictionary of English. Shanghai Foreign Language Education Press, Shanghai, 447.

[3] Tylor, E. (1871) Primitive Culture. John Murray, London, 36.

[4] Kramsch, C. (2000) Language and Culture. Shanghai Foreign Language Education Press, Shanghai.

[5] Krashen, S. (1981) Second Language Acquisition and Second Language Learning. Pergamon Press, New York.

[6] Swain, M. (1995) Three Functions of Output in Second Language Learning. In: Cook, G. and Seidlhofer, B., Eds., Principle and Practice in Applied Linguistics Studies in Honour of H.G. Widdowson, Oxford University Press, Oxford, 125-144.

[7] Harmer, J. (2000) How to Teach English. Foreign Language Teaching and Research Press, Beijing.

[8] https://en.wikipedia.org/wiki/Constructivism_(philosophy_of_education)

[9] Hall, J.K. (2005) Teaching and Researching Language and Culture. Foreign Language Teaching and Research Press, Beijing. 